\title{
CONCERNING OUDEMANS' "KRITISCH HISTORISCH OVERZICHT DER ACAROLOGIE" IN ITS BEARING ON NOMENCLATURE OF THE MOSS-MITES
}

\author{
By ARthur Paul Jacot \\ Monroe, Conn.
}

As supplements to the Tijdschrift voor Entomologie, vols. 69 and 72 (1926 and 1929), and comprising 500 and 1097 pages of text, Dr. A. C. Oudemans reprints most of the text and figures of all literature on the Acarina previous to 1805 , adding his comments and interpretations of identities. Since pre-Linnean references are of no systematic or nomenclatorial interest, they are not considered in the present review unless an earlier edition or description throws more light on a post-Linnean species of the same author. I have no faith in the descriptions or redescriptions or identifications or reidentifications of any one species by different authors in those early days, even though bearing the same specific name. This is an important principle which will be dwelt on more fully where it is a case in point. The following appear first:

\section{Acarus scaber Linné 1758}

(Oudemans, part I, pp. 347-348; part II, pp. 771-773)

In this case it is legitimate to go back to the Fauna Suecica, Ed. I (by the same author), although pre-Linnean and nonbinomial, to get the fuller description. This Linné intended us to do. It saved reprinting much material.

The words in this description "podex depressus, bidentatus" fits only some species of Michael's Nothrus, namely: $N$. bicarinatus Mich., $N$. biverrucatus Mich., $N$. targionii Mich. and $N$. segnis Mich. (without the nymphal skin). $N$. horridus is quadridentate. All these are yellow to dull brown (not dark grey), but "rough and . . . thickly 
strewn with irregular, short, villous processes" and carry much dirt so that "neither colour, texture, nor markings can be seen" (except N. targionii Mich.). Thus Linné's color and texture characters are not specific (except that they throw out $N$. targionii), the color possibly being that of the extraneous matter coating the back and the scabrousness may also be due to this "stucco."

The only species of this restricted group recorded as found in Sweden by Tragardh is N. segnis. Michael (1888, p. 514) says that $N$. biverrucatus is not common, that $N$. bicarinatus (p. 517) is common but arboreal, and that $N$. segnis (p. 521) is "chiefly found at the roots of mosses (on the ground) . . . not very common ... I have found it in Norway." In connection with Michael's figures it must be remembered that figure 1 (of N. segnis) is with nymph skin but that figure 6 (shaded portion) is what the podex looks like without the skin, thus being even more conspicuously bidentate than $N$. biverrucatus! Thus, until there is further evidence to the contrary I must regard $N$. segnis Michael a synonym of A. scaber L.

Turning to Hermann's N. segnis one is struck by the strongly bidentate podex, and the words "d'un cendré noirâtre" which immediately recalls Linné's "obscure cinereum." Finally as Hermann's figure shows the pseudostigmatic organ standing out beyond the body while in the adult they are much shorter, one must conclude that either he had before him some $N$. horridus as well as true $N$. segnis or that he figured a nymph of $N$. segnis. This latter seems still more certain from the fact that he omits the prominent rostral bristles. On the other hand, three claws are figured. As the figure is thus very evidently based on more than one individual and even more than one species, I would restrict only that part of the description and figure which refers to color (and pattern), bidentate podex and pseudostigmatic organs as type of Camisia Heyden. Acarus scaber Linné 1758 thus becomes Camisia scaber (Linné).

Oudemans's only comment is, "This description betrays at once Camisia biverrucatus C. L. Koch." This is an opinion, not evidence.

Of the 18 other references given by Oudemans, 17 of them are of relists in compilations and translations, or later 
editions or reprints and therefore of no systematic or biological interest, and one is Acarus plantarum Mayer 1781 which Oudemans considers a synonym.

Acarus plantarum Mayer is not a typical Nothrus because the abdomen is described as "at the breast somewhat compressed, broader and round towards the hind region." If it were $N$. biverrucatus or a related form, the subparallel sides and especially the two horned posterior end would have been mentioned. The color characters recall a nymph somewhat like that of $H$. bistriata Michael (1888, pl. 42, fig. 9-but this is "eyeless"!). Certainly it is not an adult, for even the legs are alternately grey and black!

\section{Acarus geniculatus Linné 1758}

(Oudemans, part I, pp. 348-353 ; part II, pp. 775-782.)

Under this head Oudemans marshals about 55 references (to 1805) many of which being non-binomial, later editions, translations and compendiums do not concern the systematist. Nine, however, were distinctly published as original descriptions of formerly unrecognized species, namely, those of 1665, 1668 (see pt. 2, p. 775), 1764 Linné (=1758), 1752, 1763 Scopoli, 1776 Schrank (=1781), 1778 DeGeer, 1799 Rathke, 1800 Shaw. Of these, those of 1665 , 1668 and 1752 are not binomial scientific names, and only Linné's is a genotype! Are these really all synonymous?

I cannot determine from these descriptions what resemblance $A$. lichenum Scopoli has to A. geniculatus. It is from Carniola (Krain, Austria), not Utrech, Holland.

A. musci Schrank 1781 (described in greater detail in 1776) from the figure looks like still another species and also comes from Austria. It will probably be many years before this species can be properly reidentified.

A. corticalis DeGeer 1778. Presumably Oudemans expects us to identify this species with the species figured by him in part I, p. 351. This can hardly be done because (1) DeGeer's species is shining (not punctured), (2) there is a distinct depression across cephaloprothorax between insertions of legs I, (3) the long bristles on legs are not on apex of tibia, (4) there are more abdominal hairs than in Oudemans's figure. As stated before (Jacot 1929g, p. 417, last paragraph), I consider DeGeer's Acarus corticalis as en- 
tirely distinct from $A$. geniculatus as the color and shape of femora are different and because $A$. corticalis was described in 1778 when DeGeer was well aware of $A$. geniculatus. Oudemans, on the other hand (part II, p. 779) claims the two to be identical and thinks it "strange" that DeGeer should have used a new name and made no mention of A. geniculatus. Since the two are described as different, DeGeer was right in giving his later find a new name. Thus we are limited to Linné only for the description of $A$. geniculatus.

Trombidium corticale Rathke 1799 is a Norwegian species which will also have to await reidentification. This should be possible by a thorough study of all Oribatids which may be found in the same type of environment in that part of Norway.

Acarus coleoptratus Shaw 1800. A comparison of his figure with that of Hooke 1665, will show considerable difference. Further, Shaw says his species is "somewhat glossy," while Hooke says "indented or pitted with an abundance of small pits, all covered over with little white bristles." Shaw distinctly shows two nails per foot, Hooke but one (yet Hooke saw punctures). The reidentification of Shaw's species will not affect nomenclature.

Thus of the six species placed by Oudemans under one term, we find that on careful examination none are synonymous.

In a similar way one may go through the remainder of his compendium. His task was stupendous and would need years of detailed work in various countries before it could be presented as a final piece of work.

One thing Oudemans has done for which Acarologists should be grateful and that is he has brought together all early references on the group and with this as a broad working basis we can each contribute our share towards clearing up certain species.

A careful perusal of Oudemans's comments on the various species reveals a well marked tendency on his part to state that the description or figures are incorrect if they do not fit the species which Oudemans has decided they should represent. This type of historical criticism carried on without a first hand knowledge of the local fauna con- 
cerned is thin ice. Each of these attempts at reidentification will have to be reconsidered without prejudice.

Oudemans has thus brought together for future study 29 pre-Hermannian species, each so poorly described as to require expert knowledge of most species at the locality from which they came or as to require their being considered nomina nuda. The list, chronologically arranged, follows.

Acarus coleoptratus Linné 1758; Sweden.

“ geniculatus same; Utrech, Holland.

“ fungorum same; Sweden.

“ scaber same; Sweden.

“ tremella Linné 1761; Sweden.

“ muscorum Scopoli 1763; Carniola (Krain, Austria).

“ lichenum same; same.

“ piger same; same.

“ spinipes O. F. Muller 1776; Denmark.

“ lichenum same; possibly an Oribatid; not Scopoli.

“ seminulum same; Denmark.

“ corticalis DeGeer 1778; Utrech, Holland.

“ marginatus same; same; not Sulzer 1776, a tick.

“ plantarum Mayer 1781; Germany.

“ conferve Schrank 1781; Austria.

“ coleoptratus Schrank 1781; same; not Linné.

“ geniculatus same; same; not Linné.

“ musci same; Austria.

“ lucidus Fourcroy 1785; France.

“ scaber Rathke 1799; Bergen, Norway; not Linné.

Trombidium corticale Rathke 1799; Bergen, Norway.

" coleoptratum same; same.

" loricatum same; same.

Acarus coleoptratus Shaw 1800; England; not Linné.

“ infusionum Schrank 1803; Bayern.

“ planicornis, xylarice ciliatus, alatus all same.

The six synonyms might be allowed to die of neglect; their reidentification would not affect subsequent nomenclature. Should a 90 per cent vote to disregard the remaining twenty-three species, cast by present day Acarologists who have studied the Oribatoidea, be considered sufficient opinion to rule these authors out of systematic literature? Or should they be retained as about 23 unavoidable nomenclatural changes for the future?

\section{References not in Oudemans.}

Michael, A. D. 1888, British Oribatidæ, vol. 2, pp. xi and 337-657. pls. $25-54$.

Jacot, A. P. 1929 (Oct.-Nov.) Genera of Pterogasterine Oribatidæ (Acarina), Trans. Amer. Micro. Soc., vol. 48, pp. 416-430. 

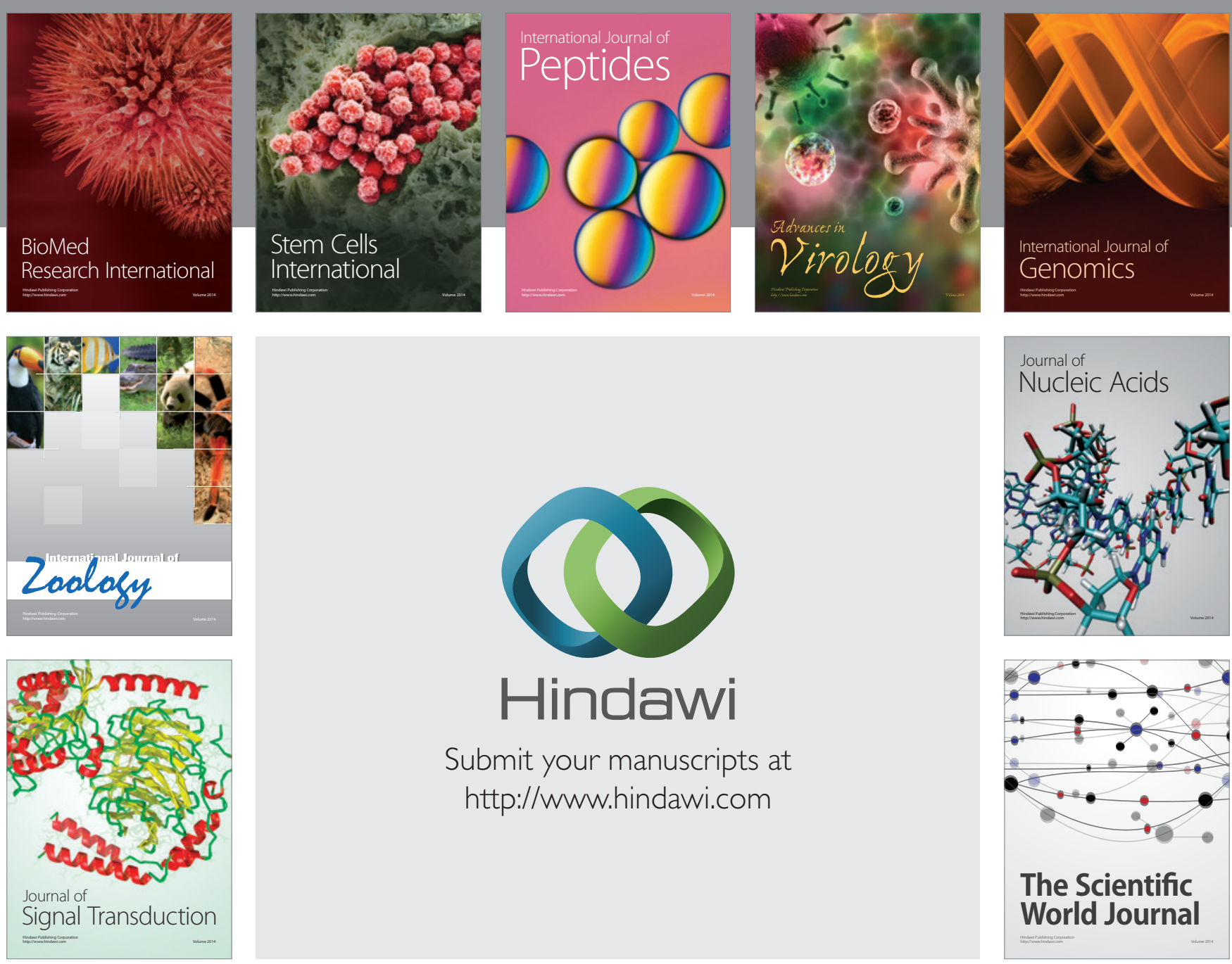

Submit your manuscripts at

http://www.hindawi.com
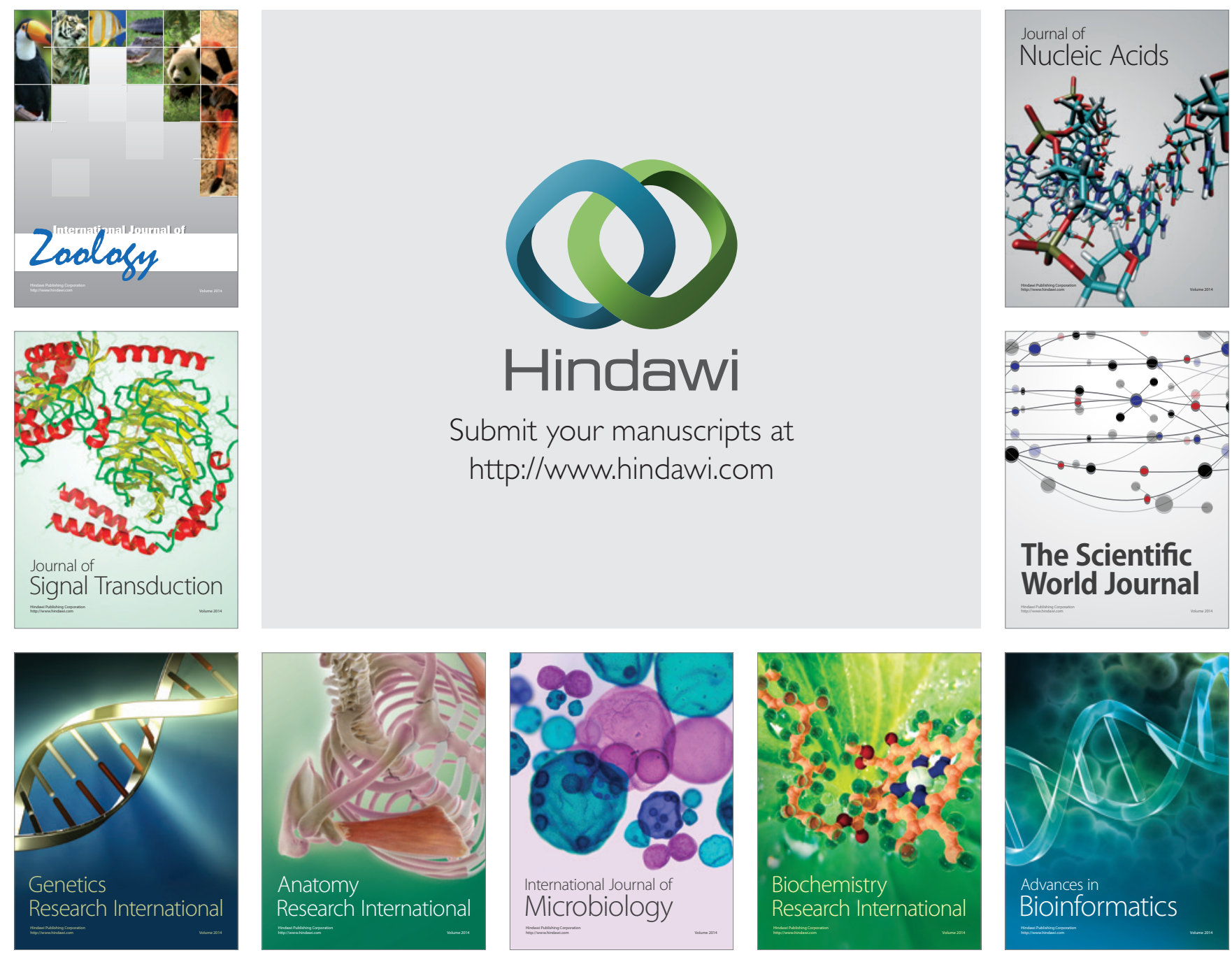

The Scientific World Journal
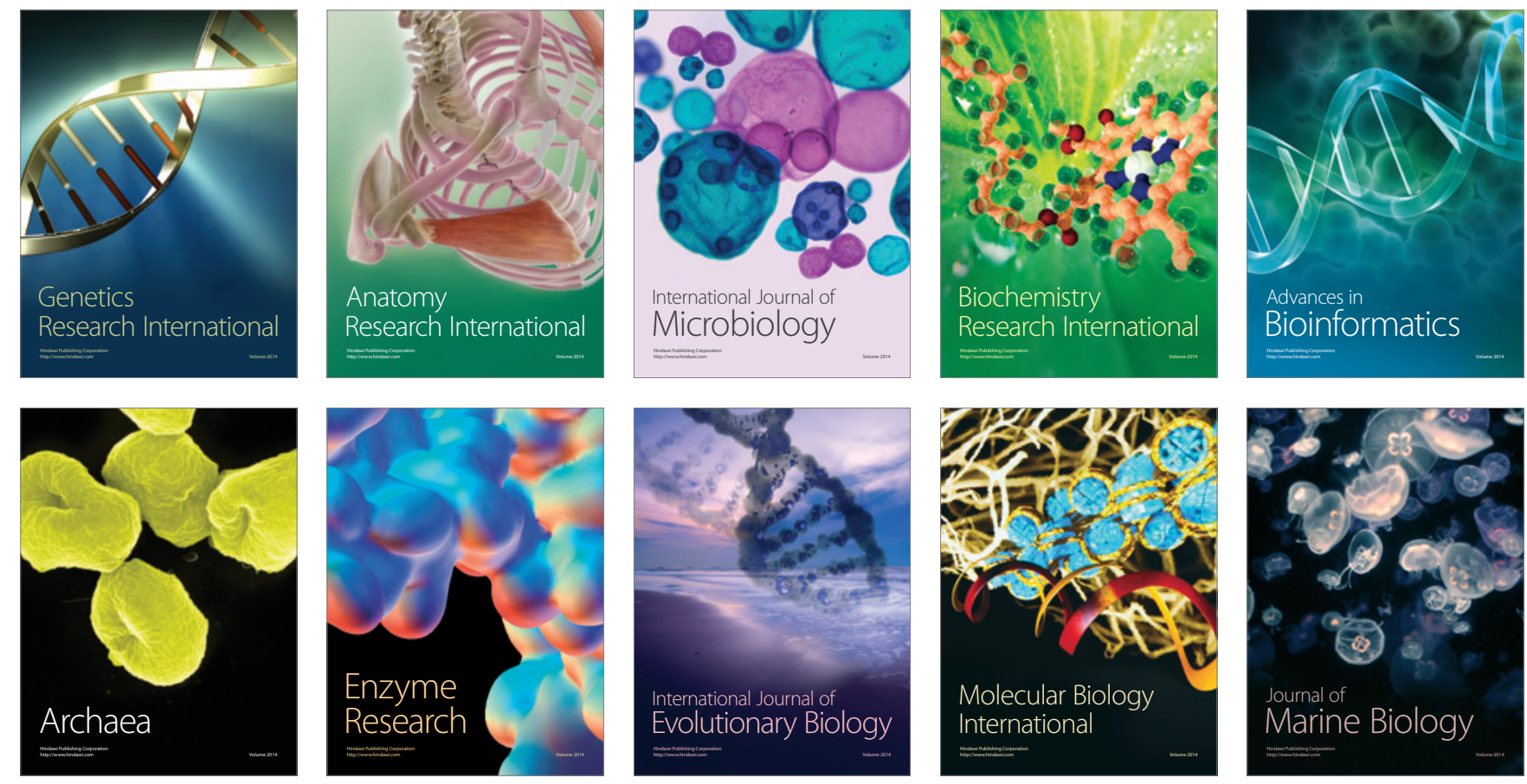